\title{
Mathematics in Latin America and the Caribbean: So Much Happening, So Much to Do
}

\author{
Luis Cáceres, José Antonio de la Peña, Angel R. Pineda, \\ Carlos Di Prisco, and Andrea Solotar
}

I n 2010, prior to the International Congress of Mathematicians (ICM) held in Hyderabad, new authorities of the Commission for Developing Countries (CDC) of the International Maththe CDC met at the new permanent office of the IMU at the Weierstrass Institute in Berlin. Part of the discussion centered on the possibility of organizing a meeting of sponsors of the IMU prior to the next ICM to be held in South Korea in August 2014. One a priori requirement was stressed for the sponsors' meeting: The IMU should know the most urgent needs of the member states and the possibilities for mathematical development. Once this was achieved, resources would be able to be identified and allocated to strategic programs such as volunteer lecturer programs. The mapping of needs and strengths would serve as a guide to what is feasible to do and where to do it. This article presents the highlights of the report on the

Luis Cáceres is professor of mathematics at the University of Puerto Rico, Mayaguez campus. His email address is 1uis.caceres1@upr.edu.

José Antonio de la Peña is full professor at the Instituto de Matemáticas of the Universidad Nacional Autóma de México and currently director general of the Centro de Investigación en Matemáticas (CIMAT) at Guanajuato, México. His email address is jap@matem. unam. mx.

Angel R. Pineda is associate professor of mathematics at California State University, Fullerton. His email address is apineda@fullerton. edu.

Carlos A. Di Prisco is investigador emérito at Instituto Venezolano de Investigaciones Científicas (IVIC) and, presently, visiting professor at Universidad de Los Andes, Bogotá. His email address is cdiprisc@ivic.gob.ve.

Andrea Solotar is professor of mathematics at Facultad de Ciencias Exactas y Naturales, Universidad de Buenos Aires and investigador principal at Instituto de Matemática Luis Santaló-CONICET. Her email address is asolotar@ dm. uba.ar.

DOI: http://dx.doi.org/10.1090/noti1169 mathematical development in Latin America and the Caribbean (LAC). The event bringing together sponsors and development projects (MENAO, Mathematics in Emerging Nations: Achievements and Opportunities) was held on August 12, 2014, in conjunction with the NANUM 2014 program in which the Korean ICM hosts invited 1,000 mathematicians from the developing world to attend the ICM. Nanum is a Korean word that means gracious and unconditional sharing.

Language, culture, and even a general approach to life are common to most countries in LAC. Some of the cultural similarities are found in the heaviness of convoluted bureaucracies and the inhomogeneous distribution of wealth, but also in optimism and hope. There are also many differences within and between countries. Here we identify some common patterns of the development of mathematics in this region while recognizing the differences.

LAC suffers from a severe shortage of financial and human resources, excruciating burdens of government incompetence, and a lack of interest in scientific development. Despite these challenges, there are success stories in the region. The average performance in the mathematical olympiads has been improving; there are strong centers of mathematical research; scientific production shows Latin America as the zone of the planet with highest growth; UMALCA, a regional organization of mathematical societies, supports many regional schools every year and promotes collaboration among mathematicians of the region. In short, there are reasons to be optimistic, but the building of a better future requires the concerted action of mathematicians and organizations (regional and global) to develop the full potential of mathematics in this region of the world. The following example illustrates both the challenges and the opportunities. 
Paraguay, a country adjacent to the more developed Argentina and Brazil, until recently had never had a graduate degree program in mathematics. At the engineering department of the National University of Asunción (UNA), UMALCA held the first school in mathematics in September 2005. Organized by a group of mathematicians including a postdoctoral associate at IMPA, the mathematics institute in Rio de Janeiro, and by representatives of the Mathematical Paraguayan Olympics (OMAPA) who coordinated the participation of high school students, the response to the UMALCA call was amazing. Not only did students from several schools participate, school teachers and engineers did also. There were newspaper articles about the event. Today at UNA, there are a Masters program in mathematics and Masters and Ph.D. programs in computer science. The first Ph.D. in the history of Paraguay graduated in 2011. In a few years the number of professional mathematicians in the country has rocketed to fifteen. In addition, there is a demand for scientific progress in the country. This led to the creation, by law of the Paraguayan Congress, of the National Fund for Excellence in Education and Research.

There are many examples, but the essence remains: some action from professional mathematicians is needed to initiate changes in policies and old structures. Our intention in creating this mapping of mathematics in LAC is to identify the most urgent needs from the region and the capacities already in place that may serve to start the action.

\section{Network of Contacts for Mapping Development}

Mapping the mathematical development in LAC required creating a network of mathematicians. These contacts were critical in getting information for smaller countries in earlier stages of development where there was no information available online. Mathematicians were identified through their involvement with the mathematical olympiads, previous conference attendance, and personal communications by the authors of this article. The mathematicians who supported this effort filled out a questionnaire which provided information beyond what could be obtained from online sources. This information was included in the summaries for each of the countries and regions in the IMU report. The list of contributors, along with their contact region. information, was a major product of this report and has already been used to both distribute information about available resources and identify local contacts to coordinate development efforts.

\section{Visualizing Mathematical Development}

The complexity of the state of mathematical research in the LAC region cannot be captured by a single number [1]. Our intent with Figure 1 is to visualize rough indicators of the untapped mathematical potential in terms of human capital (mathematical publications per capita). There is a big difference between Canada and the United States and the LAC region.

Under the assumption that mathematical talent is uniformly distributed, Figure 1 visually displays the efficiency of converting that talent into new mathematical knowledge as reflected by publications. We see a large variability in the efficiency across the LAC region. In the extremes, the number of publications per capita of Chile is approximately
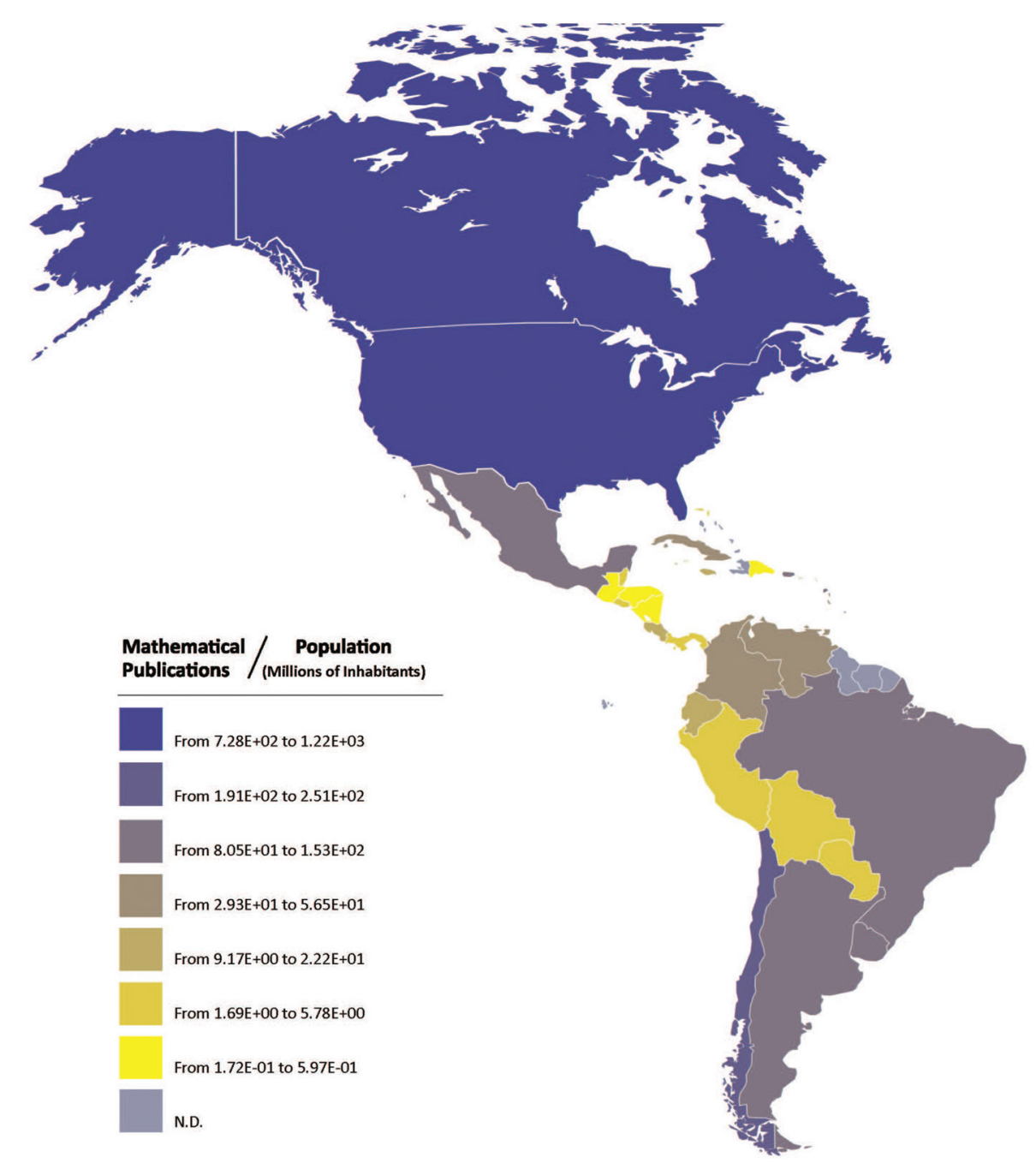

Figure 1. Map showing the per capita mathematical publications in the LAC 


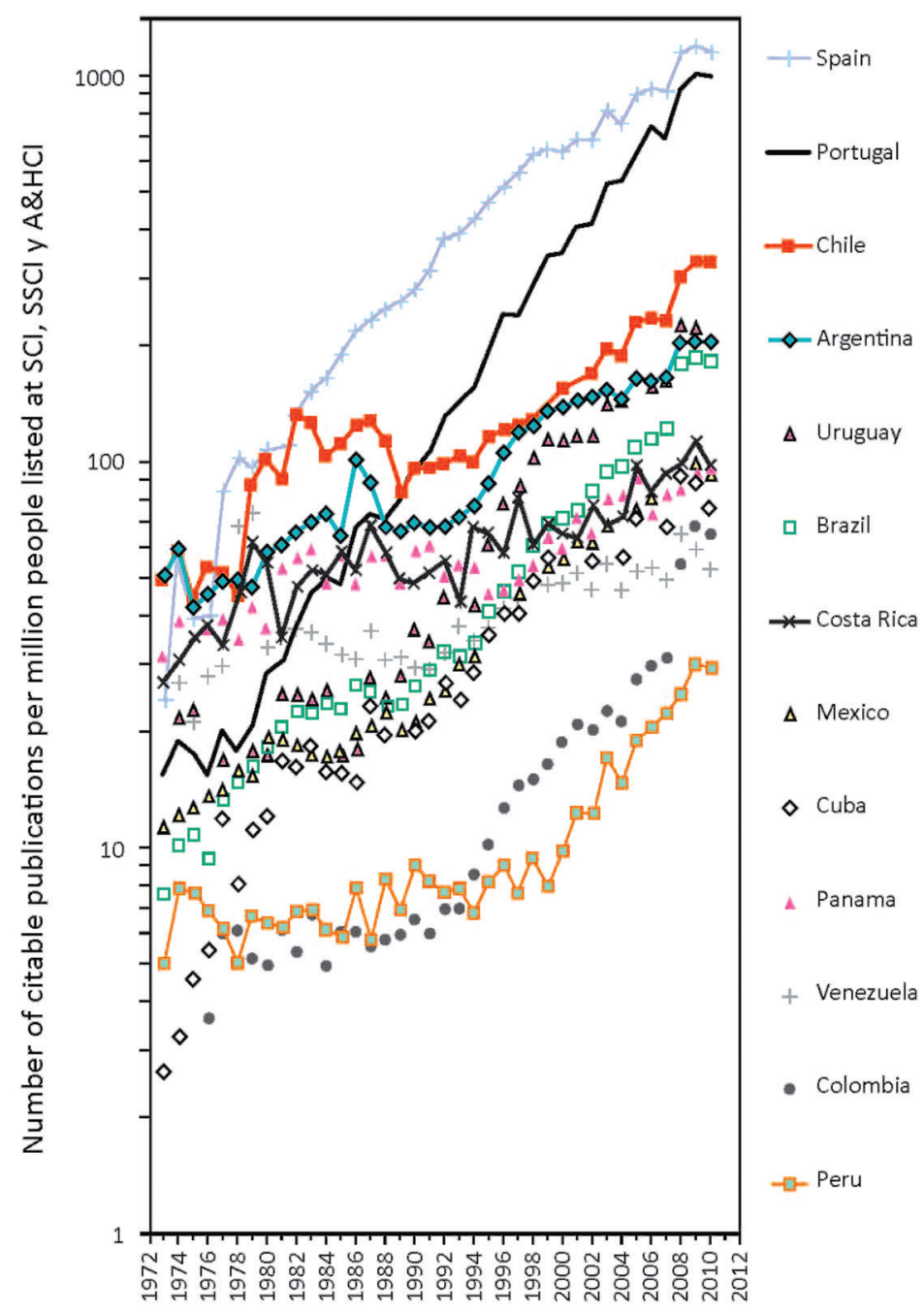

Figure 2. Number of citable publications per million people for the Iberoamerican countries with the largest number of publications.

1,450 times larger than that of Nicaragua. If we consider a country in the top 25 percent (Venezuela), it is approximately 123 times more efficient than a country in the top 75 percent (Honduras). A critical factor which leads to such a discrepancy in scientific output is whether a country has reached a development level where it can sustain a Ph.D. program in mathematics. We should also note that this measure only reflects the number of publications produced and does not account for the quality of the publications or the investment made by the governments in science.

Mexico, Brazil, Argentina, and Chile have large centers of mathematical research but also a large variability in the mathematical level within the countries. They could serve as a resource and model for mathematical development of the region. The situation in Central America is different: a population of more than forty million people has no access to a local Ph.D. program in mathematics. The Caribbean has the largest variability within LAC in terms of language and geography. There is a Ph.D. program in Puerto Rico which could serve as a resource. It is worth noting that communication among the islands has been facilitated by the mathematical olympiads.

\section{Overall Research Growth in the LAC Region}

Within the 147 most scientifically productive countries in the world, covering a ten-year plus eightmonth period (January 2000-August 31, 2010), the Iberoamerican countries included among the top twenty were Spain (ranked nine) and Brazil (ranked fifteen). Within the same period, Mexico was ranked twenty-eight, Portugal was ranked thirty-four, and Argentina was ranked thirty-five. This is an interesting improvement if we take into account that a similar survey made between 1967 and 1973 had Argentina (ranked twenty-seven), Spain (ranked twenty-nine), Brazil (ranked thirtytwo), and Mexico (ranked thirty-four) as the most productive nations of the Iberoamerican and Caribbean region [2]. Nevertheless, the scientific productivity of most of the Latin American countries, between the late 1970s and the late 1980s, remained almost constant. From the mid-1990s, most of the nations of the region began increasing their productivity again. The political and economic changes are reflected in Figure 2. For example, the jump in the productivity in Argentina in 1986 can be explained by political changes starting at the end of 1983 in that country.

Observe that Portugal has the highest growth constant of our sample. Within a period of thirtyeight years, Portugal increased its publications by a factor of seventy-six and its publications per million people by a factor of sixty-four. This dramatic change in the production of Portugal, due in part to political changes (e.g., entering the European Union in 1986), shows that, with the appropriate environment, countries in the LAC region could experience accelerated research productivity. Specifically, the growth of mathematical production in the LAC region has doubled in the span of eight years (1999 to 2007) according to the SCImago [3], [4] database. There is no other region of the world with this amount of growth in this time period.

\section{Mechanisms for Fostering Development}

Latin America and the Caribbean have large untapped potential for mathematical talent. With a better use of the region's financial and human resources and the help of more developed countries, some strategic actions could have an important effect on the development of mathematics. Here we identify some specific, relatively low cost activities that may help this development and sustainability. Most of these activities are already in practice in some countries at a good level, but their support 
and propagation could have a major impact in particular in the less mathematically developed countries. At the heart of these actions is improving the educational level of university faculty and students.

Mathematical schools (EMALCAs) organized by UMALCA and CIMPA have had a large impact on mathematical research in the region. By bringing research mathematicians to developing countries, these schools provide access to mathematical knowledge not available locally. Of a similar nature is the volunteer lecturer program of the IMU. These activities help to create a network which includes mathematicians in countries with a different level of development.

There are resources currently available for mathematicians in developing countries which are underutilized because of lack of information, for example, scholarships for study at major research centers (CIMAT, IMPA, etc.) for students from the region. A major contribution to development would be fostering a network which would help to share information about opportunities.

In several countries of the LAC region, the mathematical olympiads have been a very effective vehicle for promoting mathematics and identifying highly talented students even in remote and low-income areas. The National Mathematical Olympiad in Brazil is an event of impressive magnitude; eighteen million young people are involved, which constitutes ten percent of the country's population. Promoting increased participation in the mathematical olympiads and supporting talented students who are identified through these competitions would have a big effect on both tapping into exceptional mathematical talent in the region and increasing popular enthusiasm about mathematics.

\section{Conclusion}

Mathematics education and research are effective tools for international scientific development because, within the context of science, mathematics is inexpensive and ubiquitous. The Latin American context shows fertile ground for supporting current activities which could have a dramatic impact on educational opportunities. The broad variability in publications per capita in Figure 1 and the growth in scientific production in Figure 2 help us to see what exists and what is possible in the region.

Some specific projects that could have a major impact on the development of the region are:

- Master's level schools in less developed regions (e.g., EMALCAs),

- creation of local research networks through long-term research relationships developed through extended scientific exchanges,

- support of local Master's and Ph.D. programs to bring access to advanced education to underserved regions through volunteer lecturer programs and student scholarships,

- creating incentives for students with research education abroad to return to their home countries,

- regional mathematical olympiads.

\section{References and Notes}

[1] IMU CDC Report-Mathematics in Latin America and the Caribbean, available at http://www. mathunion. org/fi 1eadmin/CDC/cdc-uploads/CDC_MENA0/ Mathematics_in_Latin_America_and_the_ Carıbbean_Report.pdt

[2] D. J. De Solla Price, Little Science, Big Science... and Beyond, Columbia University Press, New York, 1986, pp. 192-193.

[3] SCImago Journal and Country Rank, available at http://www.scimagojr.com/.

[4] SCImago Institutional Rankings, available at http: // www.scimagoir.com/.

\section{Acknowledgments}

The authors thank their home institutions for providing the needed time to carry out this project. They also thank CIMAT for providing financial support for the work of the team, in particular, for hosting the meeting to conclude the report and for bringing together the team at the Mathematical Congress of the Americas (MCA). 